\title{
Qualitative and Quantitative Comparisons of Texture Characteristics between Broiler and Jidori-niku, Japanese Indigenous Chicken Meat, Assessed by a Trained Panel
}

\author{
Keisuke Sasaki ${ }^{1}$, Michiyo Motoyama ${ }^{1}$, Yoshio Tagawa ${ }^{2}$, Kyoko Akama ${ }^{3}$, \\ Takeshi Hayashi $^{4}$, Takumi Narita ${ }^{1}$ and Koichi Chikuni ${ }^{1}$ \\ ${ }^{1}$ Institute of Livestock and Grassland Science, National Agriculture and Food Research Organization (NARO), \\ Ikenodai 2, Tsukuba, Ibaraki 305-0901, Japan \\ ${ }^{2}$ Tottori Swine \& Poultry Experimental Station, Nambu-cho, Tottori 683-0361, Japan \\ ${ }^{3}$ Tochigi Prefecture Livestock \& Dairy Experimental Center, Nasushiobara, Tochigi 329-2747, Japan \\ ${ }^{4}$ Fukuoka Agriculture and Forestry Research Center, Chikushino, Fukuoka 818-8549, Japan
}

\begin{abstract}
The texture of jidori-niku (Japanese indigenous native chicken meat) was characterized and compared with those of Chunky broiler chicken meat. Experiment 1: A qualitative sensory test using jidori-niku and broiler breast (pectoralis major, PM), thigh (biceps femoris, BF) and sasami (deep pectoral) meat cooked to the end-point temperature $75^{\circ} \mathrm{C}$ by steam-heating was administered to a trained sensory panel $\left(n=16^{-17}\right)$ for the selection of descriptive texture items from ISO5492 texture words. By the correspondence analysis, the characteristics of 'chewiness,' 'hardness' and 'springiness' were found to be different between jidori-niku and broiler: they likely characterize jidori-niku texture. Experiment 2: Texture characteristics in the three above-mentioned muscles in jidoriniku and broiler were compared quantitatively using the three above-mentioned texture items by the trained sensory panel. Sensory chewiness and hardness were the highest in the broiler PM and second highest in the jidori-niku BF, whereas sensory springiness was the highest in the jidori-niku BF. These results suggest that jidori-niku-like texture was characterized as a springy texture as compared to broiler meat.
\end{abstract}

Key words: broiler, jidori-niku, sensory, springiness, texture

J. Poult. Sci., 54: 87-96, 2017

\section{Introduction}

Over the past few decades in Japan, both the development and the production of jidori-niku have increased in various local governments and among local producers. The word "jidori" means free-range local traditional pedigree chicken, in other words 'native chicken,' and "niku" means meat. In principle, Jidori indicates one of the Japanese native chicken breeds, similar to the breed names Shokoku and Shamo (Oka et al., 2007). However, the meaning of "jidori" changed after the Edo era (i.e., 1603-1868) and again more recently. Currently, jidori also means indigenous native chicken breeds and novel commercial special meat chickens (Sato, 2011).

Jidori-niku has been certified governmentally in the Japanese Agriculture Standards (JAS) by Japan's Ministry of

Received: April 18, 2016, Accepted: July 18, 2016

Released Online Advance Publication: August 25, 2016

Correspondence: Dr. Keisuke Sasaki, Institute of Livestock and Grassland Science, NARO, Tsukuba 305-0901, Japan. (E-mail: ksuk@affrc.go.jp)
Agriculture, Forestry, and Fisheries (MAFF). In March 2006, MAFF established 'Specific JAS Standards' including four categories of novel agricultural and animal products, such as meat products (matured hams, sausages and bacons), jidori-niku, organic foods, and products with production information (MAFF, 2006, accessed on April 4, 2016). JAS 844 defines the meaning of jidori-niku, and the definition includes genetic characteristics, feeding periods and conditions, and feeding densities.

Japanese consumers generally expect jidori-niku to differ from broiler chicken meat, based on its taste, odor, and texture characteristics (Koizumi et al., 1991). Taste characteristics in chicken meat have been previously investigated (Jayasena et al., 2013a). In particular, umami taste components such as free glutamate and inosine-monophosphate are important contributors to the taste of chicken (Fujimura et al., 1996a), whereas taste characteristics including umami are not palatability factors of jidori-niku (Fujimura et al., 1996b; Matsuishi et al., 2005).

Texture is also an important sensory characteristic in meat 
such as beef, pork, and chicken. In particular, chicken meat producers, manufacturers, and researchers generally believe that Japanese consumers have preferred jidori-niku-like ' $h a$ gotae,' which means toughness and/or firmness in comparison to broiler meat. For example, several type of local jidori-niku and brands of chicken meat have higher sensory chewiness (Matsuishi et al., 2005), instrumental shear forces (Kojima and Saegusa, 2013), and hardness (Shoji et al., 1993) than broiler meat. Koizuni et al. (1991) also reported that Japanese consumers purchased brand chicken meat including jidori-niku because of their good firmness and deliciousness. From this standpoint, various local governments in Japan aim for ha-gotae of texture characteristics in jidori chicken breeding.

In contrast, 'tenderness' is also an important sensory characteristic of meat and meat products with respect to consumers' satisfaction (Thompson, 2002). In a study of Japanese consumers, texture-liking ratings and 'tenderness' ratings were parallel (Sasaki et al., 2014). The finding that Japanese consumers generally require tender meat is inconsistent with their apparent preference for ha-gotae/firmness of jidori-niku. To improve the sensory traits of jidoriniku in response to Japanese consumers' preferences, the texture characteristics of jidori-niku should be clarified and evaluated using sensory descriptors other than 'tenderness.'

In previous research, descriptive beef texture traits were characterized using the internationally established texture vocabularies in the International Organization of Standardization's standard ISO5492, which defines terms relating to sensory analysis, and we observed that 'chewiness' and 'hardness' were distinguished in beef texture assessed by a trained sensory panel (Sasaki et al., 2010). Previous studies also revealed that Japanese consumers' perceptions of beef 'tenderness' included both chewiness and hardness as assessed by a trained panel using the ISO11036 (sensory analysis - methodology - texture profile) evaluation scales (Sasaki et al., 2013; 2014). These qualitative characterization and quantitative clarification techniques as related to consumers' perception of meat texture characteristics are useful for texture studies of other kinds of meat such as chicken meat, particularly jidori-niku.

There has been a hypothesis that there are some distinctive features in texture characteristics other than toughness and/or firmness (antonyms of 'tenderness') in jidori-niku compared to broiler meat. The goal of the present study was to characterize Japanese consumers' perception of jidori-niku-like texture. To do so, descriptive texture characteristics were compared between jidori-niku and broiler meat using qualitative and quantitative evaluations assessed by a trained sensory panel.

\section{Materials and Methods}

\section{Samples}

Satsuma jidori meat, one of the 'three major jidori-niku of Japan,' was used for jidori-niku in this study. The jidoriniku samples were obtained from a commercial farm, Jidorino-Torihama (Kanoya-shi, Kagoshima, Japan). The
Satsuma-jidori chicken were fed at this commercial farm for 120-150 days. Sample chicken carcass was treated as same as regular retail Satsuma-jidori meat products in the farm. In detail, breast, thigh, and sasami (white breast) were harvested, deboned, and vacuum packed at 0-2 p.m. after birds were sacrificed at 7-10 a.m. in the commercial farm. These vacuum-packed samples were frozen in the commercial farm at least 24 hours before shipping. For experiment 1 and 2 described below, 40 and 80 Satsuma-jidori carcasses from different flocks were obtained, respectively.

For broiler meat samples, vacuum-packed frozen bulk Chunky broiler breast, thigh and sasami meat (each package $=$ up to $2.0 \mathrm{~kg}$ ) were obtained from Marubeni Chikusan Co. (Tokyo). For experiment 1 and 2 described below, different lot of samples were obtained.

The samples were stored at $-30^{\circ} \mathrm{C}$ before the sensory experiments and thawed starting from 2 days before the sensory sessions in a refrigerator set at $4^{\circ} \mathrm{C}$. The pectoralis major (PM), biceps femoris (BF), and deep pectoral (DP) muscles were then isolated from the breast, thigh and sasami meat, respectively, and subjected to the sensory evaluations.

$\mathrm{PM}, \mathrm{BF}$, and DP muscles from at least five carcasses for jidori-niku and from at least one bulk pack for broiler meat were mixed and used as one unit of jidori-niku and broiler sample, respectively, in this study. For sample preparation, several portions were picked up from each sample unit and subjected to cooking as described below. Every replication in both experiments 1 and 2 were divided into two sessions, which were held on separate days. For each session in each replication, one sample unit was used. Thus, two units of every muscle sample such as three muscles of broiler and jidori-niku were used for every replication of sensory testing and instrumental measurements.

\section{Sample Preparation}

Chicken meat samples such as PM, BF, and DP muscles of jidori-niku and broiler meat were cooked to the end-point temperature $75^{\circ} \mathrm{C}$ by a steam-convection oven SSC-5DCNU (Maruzen, Tokyo) set at $80^{\circ} \mathrm{C}$ in the steam mode to maintain hygiene of samples. The inner temperature of the muscles and the oven temperature were monitored by a data logger, Soft-Thermo E830 (TechnolSeven, Tokyo) equipped with Tand $\mathrm{K}$ - type thermocouples for muscle and oven temperatures, respectively. Immediately after this cooking/heat treatment, the samples were chilled for at least $10 \mathrm{~min}$ in a PVC bag filled with ice-cold water to remove remaining heat. The samples were then formed into $1.5 \times 1.0 \times 0.8$-cm pieces (Experiment 1) or $1.5 \times 1.0 \times 0.5$-cm pieces (Experiments 2), the longest axis of which was parallel to the muscle fiber, and they were stored in a refrigerator set at $4^{\circ} \mathrm{C}$ placed in plastic container $\left(\right.$ Ziploc $^{\circledR}$, Asahi-Kasei corporation, Tokyo) for several hours prior to the sensory trials. For sensory and instrumental measurements, samples were subjected at room temperature without warming up in order to maintain hygiene. Sample pieces from one unit were mixed within each muscle of each chicken breed and subjected to sensory evaluation and instrumental measurements for every replication in experiment 1 and 2. 


\section{Instrumental Measurements}

An Instron Universal Testing Machine (model 5542, Instron, Canton, MA, USA) was used for the instrumental texture measurements, which were obtained by two procedures in this study. One procedure measured the shearforce values (SFVs) using a Warner-Bratzler V-blade (Insrton, Canton, MA, USA) attached to a $500 \mathrm{~N}$ compression load cell. For the SFV measurements, samples prepared as was done for Experiment 2 were sheared perpendicularly to the muscle fiber orientation by the blade with a crosshead speed of $250 \mathrm{~mm} / \mathrm{min}$. The peak force of each sample was used to determine the SFV of the sample.

The other procedure was the texture profile analysis (TPA), as described by Caine et al. (2003) with some modification, using a $4.0 \mathrm{~cm}$-dia. disk-type probe attached to the Instron 5542 testing machine as was done for the SFV measurements. Each sample underwent two cycles of $80 \%$ compression with a crosshead speed of $60 \mathrm{~mm} / \mathrm{min}$ using the Texture Profile Analysis Test Method Template (ver. 3.0; Instron). The TPA values of 'hardness,' 'gumminess,' and 'springiness' were thus calculated.

These measurements were conducted at every sensory session in Experiment 2. Therefore six units were used for instrumental analysis.

\section{Trained Sensory Panel}

For the descriptive texture evaluation, sensory panel recruiting and training were conducted as described in previous sensory texture measurement studies (Sasaki et al., 2010; 2012; 2013; 2014) with some modification and some panel member changes. Research scientists of the Animal Products Division, National Institute of Livestock and Grassland Sciences (Tsukuba-shi, Ibaraki, Japan) were recruited as sensory panelists. For Experiments 1 and 2, the number of panelists was 17 (10 males, seven female) and 16 (nine males, seven female), respectively. These panelists had experience providing descriptive sensory texture evaluations in previous studies (Sasaki et al., 2010; 2012; 2013; 2014). Additional training before experiments 1 and 2 were conducted as described below.

\section{General Procedures for the Sensory Tests}

The temperature of the test room was maintained by an airconditioner set at $21^{\circ} \mathrm{C}$. Sensory test trials were carried out at 3:00-4:00 p.m. A Latin square design was used to avoid effects of serving order. Intervals of at least $1 \mathrm{~min}$ were held between the sample tests, during which the panelist used an oral rinse made with purified water. Chicken meat samples were provided without any seasonings for all sensory sessions.

The trained sensory panel sessions were held in an individual booth illuminated by red lighting, and the untrained sensory panel sessions were held under fluorescent lightning. Immediately before each sensory session, each participant was informed of the safety of the chicken meat samples and then consented to participate in the experiments, in accord with the Japanese guidelines (National Livestock Breeding Center, 2005).

\section{Experiment 1: Qualitative Sensory Test}

In Experiment 1, six kinds of chicken meat samples (three muscles of jidori-niku and broiler meat) were subjected to a qualitative sensory evaluation as described (Sasaki et al., 2010) with modification. As an additional training, the trained panelists were lectured and instructed regarding the ISO5492: 2008 (International Organization of Standardization, 2008) texture terms and the definitions of those terms and attributes using reference foods indicated in the standard or previous study (Ohta, 2000). This additional training was for approximately one hour. Forty-one texture items for solid foods were selected from ISO5492: 2008 classified into attributes such as hardness, chewiness, gumminess, springiness, adhesiveness, conformation, and surface and inner moisture (Table 1). All items were presented to the panelists in Japanese, and examples of each texture item were obtained from a previous study (Ohta, 2000) with some modification. Evaluation guidelines including the definition and examples of each evaluation item and attribute were also presented to the panelists at each sensory trial.

For the sensory test, two pieces of samples from each muscle of jidori-niku and broiler meat were presented to each panelist. Thus, each panelist received a total of 12 pieces of samples in each trial session. The panelists tested each sample and chose the terms that were suitable for the texture of the samples. The sensory trials were repeated three times, thus a total of six units of samples were evaluated and every panelist tested three different units of samples. The frequency of selection of each texture term was logged and subjected to the statistical analysis.

\section{Experiment 2: Quantitative Sensory Test}

In Experiment 2, six chicken meat samples as described above were subjected to quantitative sensory evaluation. Prior to the sensory test, quantitative evaluation scales for chewiness, hardness, and springiness with some reference foods were established. The quantitative scales for sensory chewiness, hardness, and springiness were defined using the instrumental measurements SFV, TPA hardness, and TPA springiness assessed as described above (Table 2). As an additional training, the trained panelists used in experiment 1 were lectured and trained about these three quantitative scales using reference foods as presented in table 2 before the quantitative sensory sessions. Evaluation guidelines and reference foods (Table 2) were also presented to the panelists in each sensory trial. The samples were evaluated on linear scales from 0 to 6 or 7 for the three descriptors, as indicated in Table 2 .

For the sensory test, three pieces of samples each of each muscle of jidori-niku and broiler meat were presented to each panelist. The sensory trials were repeated three times, thus a total of six units of samples were subjected and every panelist tested three different units of samples, seminal to experiment 1.

\section{Statistical Analysis}

All statistical analyses were performed using SAS software (ver. 9.12, SAS Institute, Cary, NC). We analyzed the qualitative sensory data from Experiment 1, i.e., the fre- 
Table 1. Texture items used in the qualitative sensory evaluation (Experiment 1)

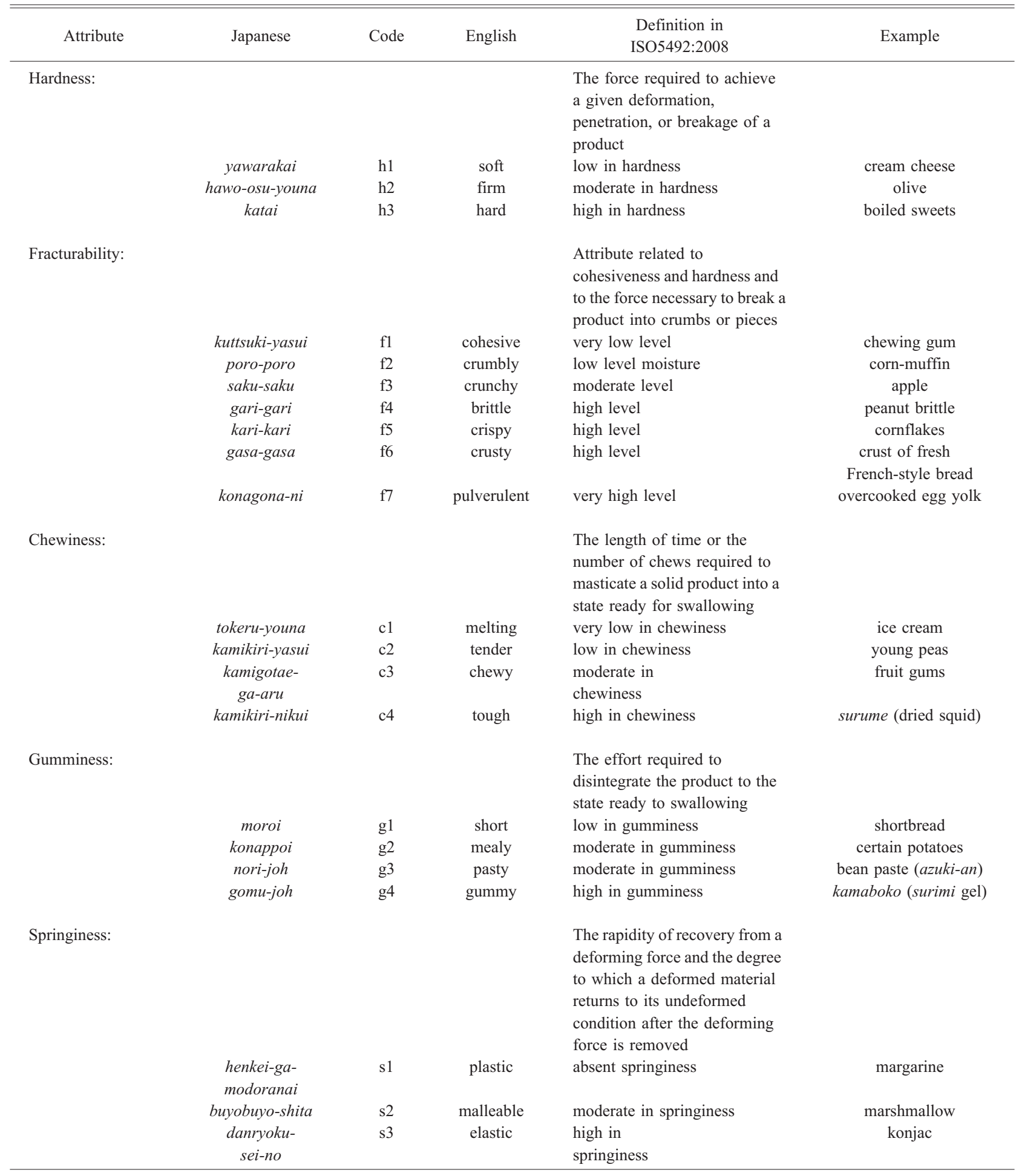

quency of the selection of each texture word in three replications by all panelists, by performing a correspondence analysis using the CORRESP procedure of the SAS program.

Experiments 2 were analyzed using the MIXED procedure of the SAS program. The type of chicken (broiler or jidori$n i k u)$, muscle parts (3 muscles), serving order and replication (3 replication for each panelist) were used as fixed effects, and panelists were used for the random effect. The Akaike 
Table 1. Texture items used in the qualitative sensory evaluation (Experiment 1) (continued)

\begin{tabular}{|c|c|c|c|c|c|}
\hline Attribute & Japanese & Code & English & $\begin{array}{l}\text { Definition in } \\
\text { ISO5492:2008 }\end{array}$ & Example \\
\hline \multirow[t]{5}{*}{ Adhesiveness: } & & & & $\begin{array}{l}\text { The force required to remove } \\
\text { material that sticks to the mouth } \\
\text { or to substrate }\end{array}$ & \\
\hline & beta-tsuku & a1 & tacky & low adhesiveness & marshmallow \\
\hline & petapeta-shita & a2 & clinging & moderate adhesiveness & peanut butter \\
\hline & nebaneba-shita & a3 & gooey & high adhesiveness & overcooked rice \\
\hline & betobeto-shita & a4 & sticky & very high adhesiveness & toffee \\
\hline \multirow[t]{6}{*}{ Conformation: } & & & & $\begin{array}{l}\text { The perception of the shape and } \\
\text { the orientation of particles in a } \\
\text { product }\end{array}$ & \\
\hline & sen'i-joh & o1 & fibrous & long conformation & chicken breast \\
\hline & saibo-joh & 02 & cellular & spherical conformation & egg white form \\
\hline & kessho-joh & o3 & crystalline & $\begin{array}{l}\text { angular, similarly sized } \\
\text { particles }\end{array}$ & granulated sugar \\
\hline & flake-joh & 04 & flaky & loose layers that separate easily & cooked tuna \\
\hline & puff-joh & 05 & puffy & $\begin{array}{l}\text { hard or firm outer shells filled } \\
\text { with large, often uneven. air } \\
\text { pockets. }\end{array}$ & cream puff \\
\hline Moisture: & & & & $\begin{array}{l}\text { The perception of water } \\
\text { absorbed by or released from } \\
\text { a product }\end{array}$ & \\
\hline \multirow[t]{3}{*}{ (Surface) } & basabasa-shita & $\operatorname{sm} 1$ & dry & none & cracker \\
\hline & shimetta & $\operatorname{sm} 2$ & moist & moderate level & peeled apple \\
\hline & nureta & $\operatorname{sm} 3$ & wet & high level & oyster \\
\hline \multirow[t]{6}{*}{ (Body) } & pasapasa-shita & bm1 & dry & absent moisture & cracker \\
\hline & shimetta & $\mathrm{bm} 2$ & moist & low-level moisture & apple \\
\hline & nureta & $\mathrm{bm} 3$ & wet & high-level moisture & mango \\
\hline & taju-joh & bm4 & juicy & high-level moisture & orange \\
\hline & shiruke-no-oi & bm5 & succulent & high-level moisture & grape \\
\hline & mizuke-no-oi & bm6 & watery & water-line perception & watermelon \\
\hline \multirow[t]{4}{*}{ Fattiness: } & & & & $\begin{array}{l}\text { The perception of the quantity } \\
\text { or the quality of fat }\end{array}$ & \\
\hline & $y u$-joh & $\mathrm{ft} 1$ & oily & $\begin{array}{l}\text { perception of soaking and } \\
\text { running fat }\end{array}$ & salad with dressing \\
\hline & aburappoi & $\mathrm{ft} 2$ & greasy & perception of exuding fat & bacon \\
\hline & $\begin{array}{l}\text { shibo-wo-ohku- } \\
\text { kanjiru }\end{array}$ & $\mathrm{ft} 3$ & fatty & $\begin{array}{l}\text { perception of high fat } \\
\text { proportion }\end{array}$ & lard \\
\hline
\end{tabular}

information criterion was used to decide on the inclusion of random effects in linear mixed models. The correlations between the three descriptive texture characteristics obtained from Experiment 2 (chewiness, hardness, and springiness) and instrumental texture traits in six observations of samples such as three muscles of broiler and jidori-niku were analyzed using the CORR procedure of the SAS program.

\section{Results}

\section{Experiment 1: Qualitative Sensory Characteristics}

The results of the correspondence analysis in Experiment 1 are presented in Figure 1. For factors 1, 2, and 3 obtained from correspondence analysis, the proportion of each factor was $56.8 \%, 31.0 \%$, and $7.1 \%$, respectively. Figure $1 \mathrm{~A}$ shows the correspondence scores of the samples. The differences between the jidori-niku and broiler samples are presented along the axis of factor 1 (horizontal axis). In contrast, factor 2 (vertical axis) was related to the differences among muscles, i.e., the PM, DP and BF muscles. This result was concluded that the factor 1 of this plot indicated the differences in the texture characteristics between jidoriniku and broiler. Factor 3 was also related to the differences among muscles, particularly PM versus other muscles (data not shown).

Figure 1B provides the coordinates of each texture word used in Experiment 1. The intensities of 'chewiness,' 'hard- 
Table 2. Scales and definitions for sensory chewiness, hardness, and springiness assessed by the trained sensory panel

\begin{tabular}{|c|c|c|c|c|c|c|c|c|}
\hline \multicolumn{3}{|c|}{ Chewiness } & \multicolumn{3}{|c|}{ Hardness } & \multicolumn{3}{|c|}{ Springiness } \\
\hline Rating & $\begin{array}{l}\text { Shear force } \\
\text { values } \\
\text { (N) }\end{array}$ & $\begin{array}{c}\text { Reference } \\
\text { food } \\
\text { or definition }\end{array}$ & Rating & $\begin{array}{c}\text { Hardness } \\
\text { by TPA } \\
\text { (N) }\end{array}$ & $\begin{array}{l}\text { Reference } \\
\text { food } \\
\text { or definition }\end{array}$ & Rating & $\begin{array}{l}\text { Springiness } \\
\text { by TPA } \\
(\mathrm{cm})\end{array}$ & $\begin{array}{l}\text { Reference } \\
\text { food } \\
\text { or definition }\end{array}$ \\
\hline 0 & & under 1 & 0 & & under 1 & 0 & & under 1 \\
\hline 1 & 1.16 & youkan & 1 & 1.94 & castella & 1 & 0.82 & $\begin{array}{l}\text { cream } \\
\text { cheese }\end{array}$ \\
\hline 2 & 11.7 & salami & 2 & 34.2 & $\begin{array}{c}\text { fish } \\
\text { sausage }\end{array}$ & 2 & 1.41 & $\begin{array}{c}\text { chocolate } \\
\text { brownie }\end{array}$ \\
\hline 3 & 23.7 & $\begin{array}{l}\text { peanut } \\
\text { chews }\end{array}$ & 3 & & $\begin{array}{c}\text { between } 2 \\
\text { and } 4\end{array}$ & 3 & 2.03 & konjac \\
\hline 4 & & over 4 & 4 & 122 & $\begin{array}{l}\text { gum } \\
\text { candy }\end{array}$ & 4 & & $\begin{array}{c}\text { between } 3 \\
\text { and } 5\end{array}$ \\
\hline 5 & & under 6 & 5 & & $\begin{array}{c}\text { between } 4 \\
\text { and } 6\end{array}$ & 5 & 2.99 & $\begin{array}{c}\text { surimi gel } \\
\text { (kamaboko) }\end{array}$ \\
\hline 6 & 56.9 & $\begin{array}{l}\text { gum } \\
\text { candy }\end{array}$ & 6 & 233 & salami & 6 & & over 5 \\
\hline 7 & & over 6 & 7 & & over 6 & & & \\
\hline
\end{tabular}

ness,' and 'springiness' decreased along the axis of factor 1. The intensities of surface and internal 'moisture' increased along the axis of factor 2 . Other texture attributes were related to neither factor 1 nor factor 2 .

From these results, three items such as 'chewiness,' 'hardness,' and 'springiness' were selected to characterize the differences in descriptive texture between jidori-niku and broiler meat.

\section{Experiment 2: Quantitative Sensory Characteristics}

Based on the results of Experiment 1, the sensory chewiness, hardness, and springiness were quantitatively analyzed using the trained sensory panel in Experiment 2. The chicken breeds affected the sensory chewiness and hardness ratings $(P<0.05)$. The difference in muscle types also affected all three texture attributes $(P<0.0001)$, and the statistical interaction between chicken breeds and muscles was observed $(P<0.0001)$ for all three texture attributes.

Figure 2 presents the quantitative values for sensory chewiness (panel A), hardness (panel B), and springiness (panel C). Sensory chewiness and hardness were the highest in the broiler PM and the second highest in the jidori-niku BF. In contrast, sensory springiness was the highest in the jidori-niku $\mathrm{BF}$ and the second highest in the broiler PM. However, the sensory springiness of the jidori-niku $\mathrm{BF}$ and that of the broiler PM did not differ from each other $(P>$ $0.05)$, unlike the sensory chewiness and hardness ratings. Within broiler samples, all of three sensory values were the highest in PM muscle, whereas these values were the highest in BF muscle within jidori-niku.

\section{Instrumental Texture Characteristics}

Effects of chicken breed, muscle, and sensory session on the instrumental texture characteristics of the meat samples subjected to the sensory evaluation in Experiments 2 were analyzed using GLM. The chicken breed affected the SFV
$(P<0.001)$. The muscle type also affected SFV and TPA hardness, gumminess, and springiness $(P<0.05)$. In addition, chicken breed and muscle type were interacted on all four instrumental texture indices $(P<0.01)$.

As shown in Figure 3, the four instrumental characteristics SFV, TPA hardness, TPA gumminess, and TPA springiness were the highest in the broiler PM and the lowest in the broiler BF samples. These four texture values were not significantly different among the three muscle types within the jidori-niku samples $(P>0.05)$, whereas intermuscular differences were observed within the broiler samples in all four instrumental characteristics $(P>0.05)$. Table 3 provides the correlation coefficients between instrumental texture indices and trained panel texture ratings. All instrumental texture characteristics significantly correlated to sensory chewiness $(P<0.05)$. SFV and TPA also correlated to sensory hardness $(P<0.05)$, whereas sensory springiness did not correlate to any instrumental texture characteristics $(P>0.05)$.

\section{Discussion}

As mentioned above, the goal of this study was to characterize the texture of jidori-niku, and to determine how it differs from that of broiler meat. Thus descriptive texture characteristics were compared qualitatively and quantitatively between jidori-niku and broiler meat. The results of experiment 1 presented qualitative texture differences due to chicken breeds and muscle types. The differences in texture were larger in the BF muscle compared to the DP and PM muscles (Fig. 1), whereas differences in quantitative sensory chewiness and hardness between jidori-niku and broiler were observed in both the BF and PM muscles assessed in Experiment 2 (Fig. 2). These differences in results between Experiments 1 and 2 may be due to the differences in experimental procedures: 42 texture items were used in Experi- 

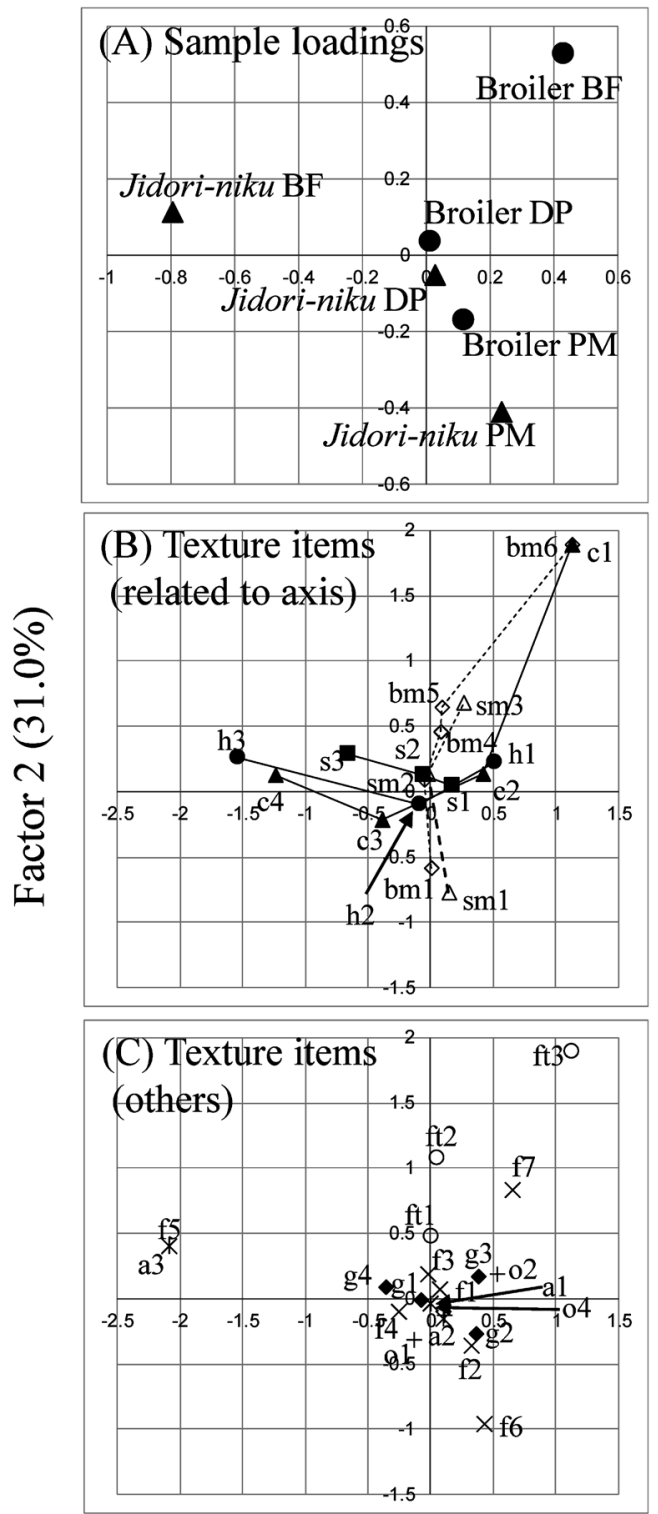

\section{Factor $1(56.8 \%)$}

Fig. 1. Correspondence analysis of texture terms for broiler and jidori-niku pectoralis major (PM), biceps femoris (BF), and deep pectoral (DP) muscles. (A): Plot of correspondence scored of each muscle sample. Closed circles and triangles indicate broiler and jidori-niku samples, respectively. (B): The coordinates for the texture items related to factors 1 and 2 . hardness, $\mathbf{\Delta}$ : chewiness, $\mathbf{\square}$ : springiness, $\triangle$ : surface moisture, and $\diamond$ : body moisture. Lowercase letters indicate the texture items by item code indicated in Table 1 . The continuous lines in the panel indicate texture attributes associated with factor 1 ( $\mathrm{x}$ axis), such as chewiness $(\mathrm{c} 1-\mathrm{c} 4)$, hardness $(\mathrm{h} 1-\mathrm{h} 4)$ and springiness $(\mathrm{s} 1-\mathrm{s} 4)$. The broken lines indicate texture attributes associated with factor 2 (y-axis) such as surface and body moistures (sm1-sm3 and bm1-bm6, respectively). (C): The coordinates for the texture items not related to factors 1 and 2 . $\diamond$ : gumminess, $\bigcirc$ : fattiness, $\times$ : fracturability, + : conformation, and *: adhesiveness. Lowercase letters indicate the texture items by item code indicated in Table 1 as same as panel (B).
(A) Sensory chewiness

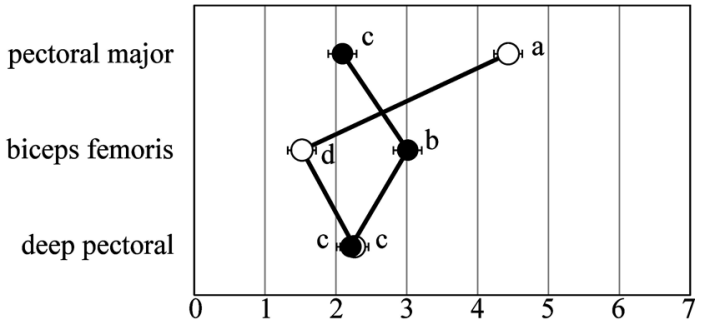

(B) Sensory hardness

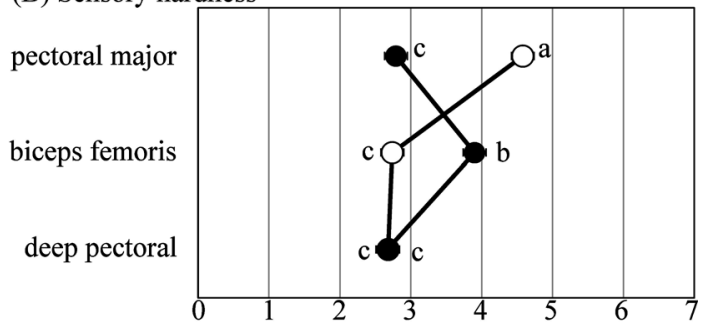

(C) Sensory springiness

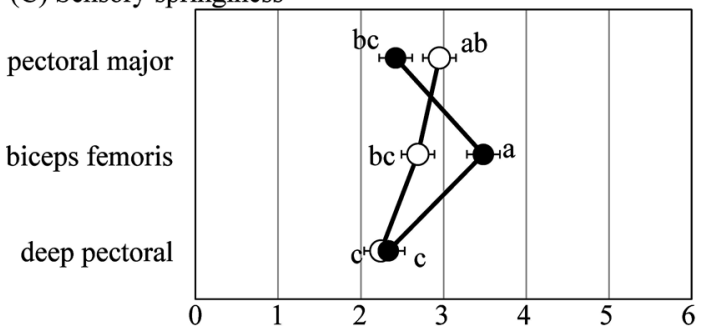

Fig. 2. Sensory chewiness (A), hardness (B), and springiness $(\mathrm{C})$ ratings of broiler and jidori-niku $\mathrm{PM}, \mathrm{BF}$, and DP muscles assessed by the trained sensory panel. Open circles indicate broiler meat and closed circles indicate jidori-niku meat. Values are expressed as least squares means \pm SEM. Values with different superscripts within each panel differ significantly $(P<0.05)$.

ment 1, whereas only three items were used for sensory testing in Experiment 2.

Results from experiment 2 indicate that the differences in descriptive texture characteristics between the BF and PM muscles were not the same between the jidori-niku and broiler meat (Fig. 2). In the BF muscle, chewiness and hardness were higher in the jidori-niku than in the broiler meat, whereas the chewiness and hardness values for the PM muscle were higher in the broiler meat than the jidori-niku meat. Various studies compared the texture between indigenous native and broiler chicken meat. Some of these studies reported that the differences in texture characteristics between breast and thigh meat were not similar in native and commercial broiler chicken meat. For example, with the use of samgyetang cooking, the tenderness characteristics of Korean native chicken meat differed from those of broiler meat in thigh meat, but did not differ in breast meat (Jayasena et al., 2013b). Thai native chicken breast meat was reported to be tougher than broiler breast meat, but these toughness values did not differ in thigh meat (Jaturasitha et al., 2008). 

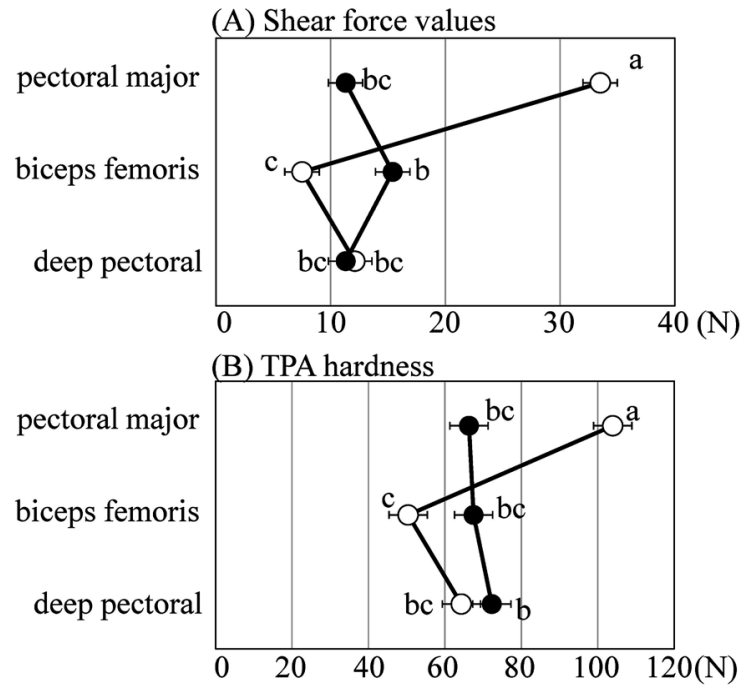

(C) TPA gumminess

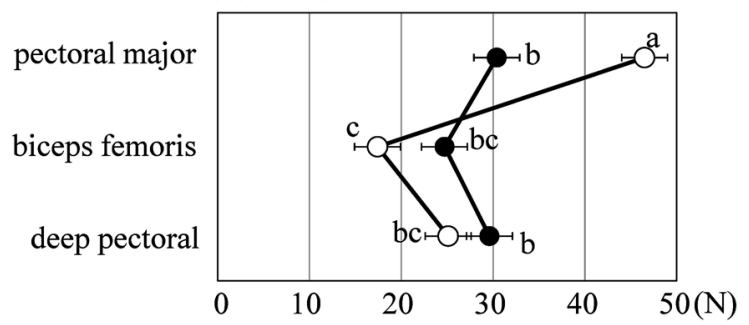

(D) TPA springiness

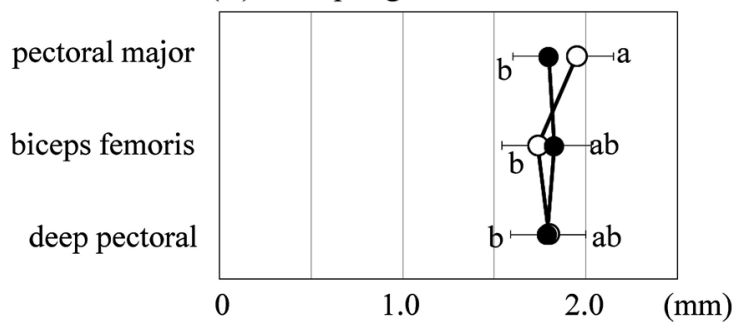

Fig. 3. Instrumental texture characteristics of broiler and jidori-niku PM, BF, and DP muscles. A: ShearForce values, B: Texture profile analysis (TPA) hardness. C: TPA gumminess. D: TPA springiness. Open circles indicate broiler meat and closed circles indicate jidori-niku meat. Values are least squares means \pm SEM. Values with different superscripts within each panel differ significantly $(P<0.05)$.

For texture investigations of chicken meat, breast meat (i.e., PM muscle) has often been used as the sample (e.g., Le Bihan-Duval et al., 2008; Smith et al., 1998; Wakefield et al., 1989; Yoon, 2003), perhaps because the PM is a useful muscle for experimental measurements due to its largest size in the chicken carcass. However, to characterize native chicken texture and other sensory traits in comparisons with broiler chicken meat, multiple muscles, not only the PM muscle, should be used for sensory and instrumental measurements. In addition, experiment 2 employed only limited cooking condition such as the end-point temperature $75^{\circ} \mathrm{C}$ by a steam-cooking. It has been generally understood that cooking procedures, particularly cooking end-point temperature, strongly affect texture characteristics of meat. Effects of cooking conditions on the differences between texture characteristics of jidori-niku and broiler meat should be examined in further studies.

Descriptive sensory characteristics assessed by a trained sensory panel are often not in agreement with untrained consumer perceptions, because untrained consumers have a limited vocabulary to express sensory perceptions (Muñoz, 1998). Thus preliminary experiment using 33 untrained panelists to evaluate jidori-niku like texture using their own criteria was conducted. This preliminary experiment suggested that the jidori-niku-like texture judged by the untrained panel was characterized as 'chewy, hard, and springy texture' (data now shown). However, 33 panelist is not enough to investigate consumers' perception for jidori-nikulike texture.

As described above, the 'tenderness' of meat is an important texture characteristic for consumers' satisfaction (Thompson, 2002). In contrast, Japanese consumers expect good firmness for jidori-niku (Koizumi et al., 1991). Because Font-i-Furnols and Guerrero (2014) pointed out that the development of consumers' expectations for meat depends on the type of meat or meat products and on the context of the product, it is not surprising that among Japanese consumers the expectations for jidori-niku meat differ from those for broiler meat. However, the relationship between texture-liking in the untrained panel and objective factors related to jidori-niku like texture have not been clarified yet. Sasaki et al. (2014) also indicated that the criteria of consumers' tenderness perception and texture likings differ from person to person. Expectations and likings for texture in chicken meat may also be diverse among Japanese consumers. Further research should be conducted to determine the relationship between sensory descriptive texture data and consumer acceptability of jidori-niku chicken.

Moreover, this study used commercial bulk-packaged broiler meat as a reference sample for sensory and instrumental analysis after freezing storage. It has been well known that postmortem processing of chicken meat, in particular postchill deboning time, affect sensory texture characteristics in breast (Lyon et al., 2003) and thigh (Zhuang and Savage, 2011) meat. Effects of postmortem processing conditions should also be investigated on sensory chewiness, hardness, and springiness assessed in the present study. In addition, further studies using samples without freezing storage should also be conducted.

To maintain the special texture characteristics of jidori$n i k u$, a prediction system for jidori-niku-like texture using instrumental measurements should be developed. However, sensory chewiness and hardness correlated to instrumental texture characteristics whereas springiness did not correlate with the any machinery texture measurements (table 3). Grunert et al. (2004) pointed out that additional information such as the brand of the food may play an important role in the formation of expected eating quality. For the quality 
Table 3. Correlation coefficients between trained panel texture ratings, untrained panel ratings, and instrumental texture measurements

\begin{tabular}{|c|c|c|c|c|c|c|}
\hline & \multicolumn{2}{|c|}{ Trained Panel Ratings } & \multicolumn{4}{|c|}{ Instrumental Measurements } \\
\hline & Hardness & Springiness & SFV & $\begin{array}{c}\text { TPA } \\
\text { hardness }\end{array}$ & $\begin{array}{c}\text { TPA } \\
\text { gumminess }\end{array}$ & $\begin{array}{c}\text { TPA } \\
\text { springiness }\end{array}$ \\
\hline \multicolumn{7}{|l|}{ Trained panel: } \\
\hline Chewiness & $0.939 * *$ & $0.515^{\mathrm{ns}}$ & $0.977 * * *$ & $0.937 * *$ & $0.866^{*}$ & $0.987 * * *$ \\
\hline Hardness & & $0.759^{\mathrm{ns}}$ & $0.901 *$ & $0.788^{\mathrm{ns}}$ & $0.694^{\mathrm{ns}}$ & $0.894 *$ \\
\hline Springiness & & & $0.402^{\mathrm{ns}}$ & $0.230^{\mathrm{ns}}$ & $0.101^{\mathrm{ns}}$ & $0.403^{\mathrm{ns}}$ \\
\hline \multicolumn{7}{|c|}{ Instrumental measurements: } \\
\hline SFV & & & & $0.956^{* *}$ & $0.908 *$ & $0.986 * * *$ \\
\hline TPA hardness & & & & & $0.977 * * *$ & $0.963 * *$ \\
\hline TPA gumminess & & & & & & $0.923 * *$ \\
\hline
\end{tabular}

ns: not significant, $* P<0.05, * * P<0.01, * * * P<0.001$. SFV: shear force values. TPA: Texture Profile Analysis.

control and the descriptive labeling of jidori-niku-like texture to enhance consumers' expectation and satisfaction, further studies are needed to determine a method for accurately predicting jidori-niku-like texture using objective instrumental measurements.

\section{Acknowledgments}

This study was partially supported by the Japan Society for the Promotion Science (JSPS), Grant-in-Aid (KAKENHI) for Young Scientists (B), 203700898 (2011-2014). The authors sincerely thank Yumiko Endo and Akemi Shimizu, Institute of Livestock and Grassland Science, NARO, for their generous assistance, and also thank the research scientists of the Animal Products Division of NILGS for their contribution as trained sensory panelists.

\section{References}

Caine WR, Aalhus JL, Best DR, Dugan MER and Jeremiah LE. Relationship of texture profile analysis and Warner-Bratzler shear force with sensory characteristics of beef rib steaks. Meat Science, 64: 333-339. 2003.

Font-i-Furnols $\mathrm{M}$ and Guerrero L. Consumer preference, behavior and perception about meat and meat products: An overview. Meat Science, 98: 361-371. 2014.

Fujimura S, Koga H, Takeda H, Tone N, Kadowaki M and Ishibashi T. Role of taste-active components, glutamic acid, 5'-inosinic acid and potassium ion in taste of chicken meat extract. Japanese Journal of Zootechnical Science, 67: 423-429. 1996a.

Fujimura S, Koga H, Takeda H, Tone N, Kadowaki M and Ishibashi T. Chemical compositions of pectoral meat of Japanese native chicken, Hinai-jidori, and broiler of the same and marketing age. Japanese Journal of Zootechnical Science, 67: 541-548. $1996 \mathrm{~b}$

Grunert KG, Bredahl L and Brunsø,K. Consumer perception of meat quality and implications for product development in the meat sector - a review. Meat Science, 66: 259-272. 2004.

International Organization of Standardization. ISO5492:2008 Sensory analysis - Vocabulary. International Organization of Standardization. Geneva. 2008.

Jaturasitha S, Srikanchai T, Kreuzer M and Wicke M. Differences in carcass and meat characteristics between chicken indigenous to northern Thailand (Black-boned and Thai native) and imported extensive breeds (Bresse and Rhode Island Red). Poultry Science, 87: 160-169. 2008.

Jayasena DD, Ahn DU, Nam KC and Jo C. Factors affecting cooked chicken meat flavor: a review. World Poultry Science, 69: 515-526. 2013a

Jayasena DD, Jung S, Kim HJ, Bae YS, Yong HI, Lee JH, Kim JG and Jo C. Comparison of quality traits of meat from Korean native chickens and broilers used in two different traditional Korean cuisines. Asian-Australasian Journal of Animal Sciences, 26: 1038-1046. 2013b.

Koizumi S, Nishino M and Nagano M. Studies on the consumer behavior for animal products - XIV-An investigation on chicken meat (in Japanese). Bulletin of College of Agriculture and Veterinary Medicine, Nihon University, 48: 140-153. 1991.

Kojima S and Saegusa H. Physicochemical properties in meat of Tokyo-ukokkei, Japanese Silky Fowl - Comparison with meattype chickens (in Japanese). Bulletin of Tokyo Metropolitan Agriculture and Forestry Research Center, 8: 11-18. 2013.

Le Bihan-Duval E, Debut M, Berri CM, Sellier N, Santé-Lhoutellier $\mathrm{V}$, Jégo $\mathrm{Y}$ and Beaumont $\mathrm{C}$. Chicken meat quality: genetic variability and relationship with growth and muscle characteristics. BMC Genetics, 9: 53. 2008.

Lyon CE, Lyon BG and Savage EM. Effect of postchill deboning time on the texture profile of broiler berrder hen breast meat. Journal of Applied Poultry Research, 12: 348-355. 2003.

Matsuishi M, Kato A, Ishige N, Hori T, Ishida Y, Kaneko S, Takenonaka M, Miyamura Y, Iwata T and Okitani A. Comparison of meat palatability factors of Nagoya Cochin with broiler and Aigamo (in Japanese). Nihon Chikusan Gakkaiho, 76: 423-430. 2005.

Ministry of Agriculture, Forestry and Fisheries. Specific JAS Standards. http://www.maff.go.jp/e/jas/specific/index.html. Accessed on April 4, 2016.

Muñoz AM. Consumer perceptions of meat. Understanding these results through descriptive analysis. Meat Science, 49: S287S295. 1998.

National Livestock Breeding Center. Guidelines for sensory evaluation of meat (in Japanese). Japan Meat Information Service Center. Tokyo. 2005.

Oka T, Nomura K, Kawashima S, Kuwayama T, Hanada H, Amano 
T, Takada M, Takahata N, Hayashi Y and Akishinonomiya F. Analysis of mtDNA sequences shows Japanese native chickens have multiple origins. Animal Genetics, 38: 287-293. 2007.

Ohta Y. Expression of texture sensation (in Japanese). Japanese Journal of Sensory Evaluation, 4: 21-27. 2000.

Sasaki K, Motoyama M, Yasuda J, Yamamoto T, Oe M, Narita T, Imanari M, Fujimura $\mathrm{S}$ and Mitsumoto $\mathrm{M}$. Beef texture characterization using internationally established texture vocabularies in ISO5492:1992: Differences among four different endpoint temperatures in three muscles in Holstein steers. Meat Science, 86: 422-429. 2010.

Sasaki K, Motoyama M and Natira T. Increased intramuscular fat improves both 'chewiness' and 'hardness' as defined in ISO5492: 1992 of beef longissimus muscles of Holstein $\times$ Japanese Black F1 steers. Animal Science Journal, 83: 338343. 2012.

Sasaki K, Motoyama M, Narita T and Chikuni K. Effects of cooking end-point temperature and muscle part on sensory 'hardness' and 'chewiness' assessed using scales presented in ISO11036: 1994. Asian-Australasian Journal of Animal Sciences, 26: 1490-1495. 2013.

Sasaki K, Motoyama M, Natira T, Hagi T, Ojima K, Oe M, Nakajima I, Kitsunai K, Saito Y, Hatori H, Muroya S, Nomura M, Miyaguchi Y and Chikuni K. Characterization and classification of Japanese consumer perceptions for beef tenderness using descriptive texture characteristics assessed by a trained sensory panel. Meat Science, 96: 994-1002. 2014 (Corrigendum: Meat Science, 103: 104. 2015).

Sato S. Origin and definition of Japanese native chickens, "jidori" (in Japanese). Journal of the Japanese Society on Poultry Diseases, 47: 1-11. 2011.

Shoji T, Horikawa H, Fueki M, Nagaoka T and Takayama H. Physico-chemical properties of the shallow chest meats on broiler and crossbred of small Shamo and Nagoya (in Japanese). Hokuriku Journal of Zootechnical. Science, 66: 52-56. 1993

Smith DP, Lyon CE and Fletcher DL. Comparison of the AlloKramer shear and Texture Profile methods of broiler breast meat texture analysis. Poultry Science, 67: 1549-1556. 1998.

Thompson J. Managing meat tenderness. Meat Science, 62: 295308. 2002.

Wakefield DK, Dransfield E, Down NF and Taylor AA. Influence of post-mortem treatments on turkey and chicken meat texture. International Journal of Food Science and Technology, 24: 81-92. 1989.

Yoon KS. Effect of irradiation on the texture and microstructure of chicken breast meat. Meat Science, 63: 273-277. 2003.

Zhuang $\mathrm{H}$ and Savage EM. Effect of postmortem deboning time on sensory descriptive flavor and texture profiles of cooked boneless skinless broiler thighs. LWT - Food Science and Technology, 44: 2087-2090. 2011. 